\title{
Sperm function tests in clinical practice
}

\author{
Fuat Kızılay, Barış Altay
}

Cite this article as: Kızılay F, Altay B. Sperm function tests in clinical practice. Turk J Urol 2017; 43(4): 393-400

Department of Urology, Ege University School of Medicine, İzmir, Turkey

Submitted:

24.07.2017

Accepted:

07.08.2017

Correspondence:

Fuat Kızılay

E-mail:

fuatkizilay@gmail.com

(C) Copyright 2017 by Turkish

Association of Urology

Available online at www.turkishjournalofurology.com

\begin{abstract}
Conventional semen analysis solely is not completely adequate to predict pregnancy outcomes. Therefore, advanced sperm function tests have been developed and introduced to clinical practice. These tests use different methods and techniques to evaluate different stages of fertilization steps. In this review, we reported some commonly used sperm function tests: sperm penetration assay, sperm-zona pellucida binding test (hemizona assay), acrosomal reaction test, hyaluronan binding test, hypo-osmotic swelling test, magneticactivated cell sorting and zeta sperm selection. We discussed the literature concerning these tests, the utilization techniques and also purpose and mechanism of each test. We emphasized the importance of sperm function tests in predicting in vitro fertilization and pregnancy outcomes and in the management of infertile couples and also the limitations of these tests. Along with improvements in molecular biology techniques, we believe that more applicative and beneficial tests will be developed in the near future.
\end{abstract}

Keywords: In vitro fertilization; male infertility; sperm functional test.

\section{Introduction}

Conventional semen analysis (SA) can not exactly reveal a man's fertility potential. Conventional SA, based on sperm motility and macroscopic evaluation, may not accurately reflect the fertilization ability of the spermatozoa. SA may classify an infertile man according to the type and degree of his spermatogenetic defect, but provides limited information about how well a sperm will function in in vitro or in vivo settings. The basic SA has limited predictive value for pregnancy outcome in couples both trying to achieve conception with or without using assisted reproductive technology (ART).$^{[1]}$ More importantly, men with normal SA may be infertile or fertile. ${ }^{[2]}$ This indicates that more comprehensive sperm function tests should be performed.

During the last two decades, intracytoplasmic sperm injection (ICSI) has become the preferred technique in patients with a history of previously unsuccessful conventional in vitro fertilization (IVF) and male factor infertility. It has been shown that the semen parameters of unprocessed ejaculate do not affect ICSI results. Therefore, it is important to identify the sperm dysfunction at the cellular and molecular level.

Ideally, the sequential analysis of sperm functions can help the clinicians in planning therapeutic approach. ${ }^{[3,4]}$ However, up to date, assessment of sperm function tests has failed to make such a significant impact on the clinical management of infertile couples. Lack of standardized protocols has been the main reason..$^{[5]}$

An ideal sperm function test should diagnose a specific sperm dysfunction, predict fertilization and pregnancy rates and indicate an appropriate therapy to alleviate the identified sperm dysfunction. The World Health Organization (WHO) qualified sperm function tests as 
research tests. ${ }^{[6]}$ These tests were originally designed to evaluate the fertility potential of spermatozoa in vitro. But, over time, these tests have become more predictive assays for pregnancy. IVF results have shown that defective acrosomal reaction and/or abnormal sperm-zona pellucida relation are frequently found in sperm of infertile males. Ejaculated sperm must undergo capacitation, recognize, bind to the zona pellucida (ZP) and finally undergo acrosome reaction to fertilize the ovum. Therefore, sperm function tests aim to evaluate the steps of fertilization: (i) sperm binding to $\mathrm{ZP}$, (ii) acrosomal exocytosis, (iii) and fusion with the vitelline membrane of the oocyte (Figure 1).

The acrosome reaction is induced by spermatozoa-ZP binding, right after the lytic acrosomal enzymes are released, and the spermatozoa proceed to the zonal matrix with increased flagellar motility. Sperm-ZP binding tests including sperm-zona binding test and hemizona test (HZA) and acrosome reaction tests have been shown to provide clinically significant information to predict IVF results. The highest specificity and sensitivity associated with sperm-ovum interaction are also provided by the sperm-ZP binding tests. Although there is a significant relation between the in vitro results of these tests and fertilization, there are problems about their utilization in routine clinical practice such as difficulties in terms of requirement for human material requirement, challenging occasionally time-consuming and expensive techniques.

The aim of this review is to evaluate and review the clinical utilization of sperm function tests, especially gamete interaction tests.

\section{Sperm penetration assay}

Sperm penetration assay (SPA) is one of the first sperm function tests developed. ${ }^{[7]}$ In this heterologous bioassay, human spermatozoa are subjected to the hamster oocytes which are devoid of ZP



Figure 1. Steps of fertilization
(Figure 2). SPA measures the capacitation ability of spermatozoa, acrosome reaction, fusion and penetration through the oolemma and decondensation within the cytoplasm of hamster oocytes. ${ }^{[8]}$ Vogiatzi et al. ${ }^{[9]}$ reported higher sensitivity (52\%-100\%), specificity (0-100\%) and positive predictive value (PPV; 18\%-100\%) and negative predictive value (NPV; $0-100 \%)$ in terms of the diagnostic accuracy of SPA. The standardization and reproducibility of this assay is low. SPA differs from the physiological situation where $\mathrm{ZP}$ is absent during the procedure. Oehninger et al. ${ }^{[8]}$ carried out a meta-analysis of sperm function tests to evaluate their predictive value for (IVF) outcomes. They revealed that SPA had a poor clinical value as a indicative of fertilization after analysis of 2.906 cycles, with high sensitivity but high false-positive rates. ${ }^{[10]}$ Another meta-analysis collected data on 647 patients in 24 studies. A summary receiver operating characteristics (ROC) curve demonstrated that the sensitivity of SPA was only $37 \%$, with a specificity of $95 \%$ and the authors concluded that performing SPA is insufficient for selecting patients for treatment with IVF-embryo transfer. ${ }^{[11]}$ False-negative results (the spermatozoa fails to respond to SPA but fertilizes the egg successfully) have been also frequently reported.

The anticipation that the strength of the SPA test can be improved with some modifications is not exactly verified. ${ }^{[12]}$ This expensive and time-consuming test should conceivably not be routinely used to determine fertility potential until the reproducibility and reliability of the test is improved.

\section{Sperm-zona pellucida binding tests}

The relation between spermatazoa and ZP is highly critical and indicates many features of sperm function. Some of these functions are achievement of the capacitation and the getting ready for the beginning of the acrosome reaction. ${ }^{[13,14]} \mathrm{HZA}^{[15]}$ and a competitive intact zona sperm binding assay ${ }^{[16]}$ are the two most commonly used sperm-ZP binding tests (Figure 3). Although

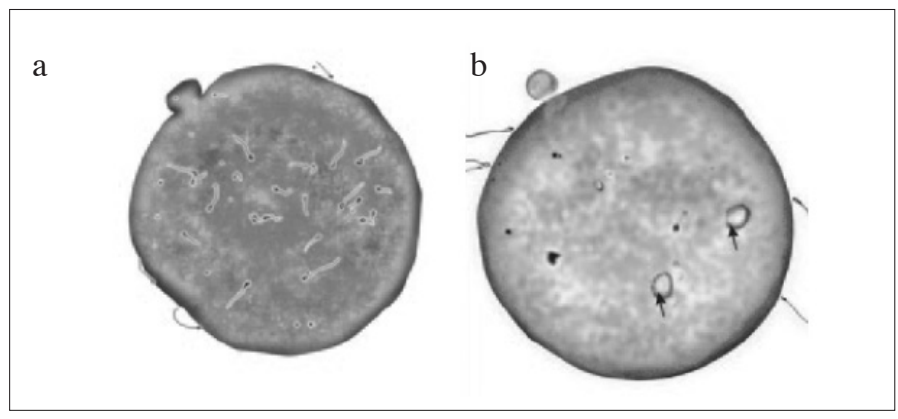

Figure 2. a, b. Illustration of sperm penetration assay. (a) Human spermatozoa are seen in the hamster oocyte cytoplasm. (b) Arrows show sperm heads swelling in the oocyte cytoplasm, indicating sperm decondensation 
the methodologies are different, they evaluate the tight binding of sperm to ZP as primary outcome. They revealed a high predictive value for successful IVF outcomes. ${ }^{[13,17]}$ Impaired spermzona binding and zona penetration in conventional IVF are the most common causes of fertilization failure. In oligozoospermic patients, $80 \%$ of sperm can not normally bind to ZP. ${ }^{[18]}$

Hemizona test is an internally controlled assay and uses matching halves of a human ZP. ${ }^{[19]} \mathrm{HZA}$ should be used in cases with severe oligoastenozoospermia where recurrent lower or failed fertilization rates were obtained with IVF treatment. In addition, oligozoospermic men were shown to be quite risky of having defective sperm-ZP associations. ${ }^{[20]}$

In the HZA test, sperm of fertile men is used as a control because it shows higher binding capacity than infertile male sperm. HZA results are interpreted by an index called hemizona index (HZI). The HZI is the ratio between bound sperm of subfertile men and bound sperm of fertile men (HZI = bound sperm from subfertile male divided by bound sperm from fertile male $x$ 100). ${ }^{[15,21]}$ Prospective studies reported a HZI of $35 \%$ as a predictive value of ICSI outcome. ${ }^{[22,23]}$ It has been shown that a HZI of $<30$ leads to significantly lower pregnancy rates after intrauterine insemination (IUI) treatment, compared to HZI of $>30 .^{[24]}$ Oehninger et al. ${ }^{[25]}$ concluded in their review that HZA has an excellent predictive power for the outcomes of IUI and IVF, and therefore the assay has a relevance in the clinical diagnostic setting in infertility.

\section{Zona pellucida glycoproteins}

During sperm-oocyte interaction, acrosome-intact sperm bind to the $\mathrm{ZP}$ and $\mathrm{ZP}$ induces the acrosome reaction (AR). ${ }^{[26]}$ There

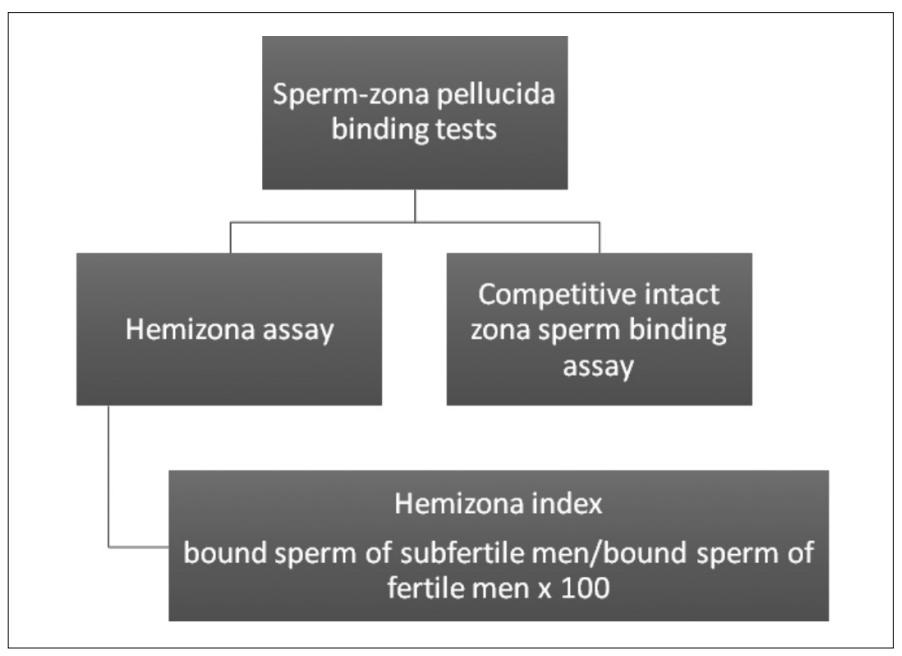

Figure 3. Most commonly used sperm-zona pellucida binding tests are four glycoproteins in the human ZP: hZP1, hZP2, hZP3 and hZP4. ${ }^{[27]}$ Although ZP3 and ZP4 are proposed to act as primer $\mathrm{ZP}$ receptors necessary for the initiation of $\mathrm{AR}$, experimental studies have shown that other $\mathrm{ZP}$ proteins are also required for human spermatozoa-oocyte relation. ${ }^{[28]}$

Occasionally, normozoospermic infertile men have normal sperm-ZP binding but, failed sperm-ZP penetration. This is mostly secondary to impaired ZP-induced AR (DZPIAR) that causes sperms to bind to the $\mathrm{ZP}$ but fails to induce AR on the ZP ${ }^{[29]}$ Liu et al. ${ }^{[30]}$ enrolled 51 DZPIAR infertile men in their study and reported that defective protein kinase $\mathrm{C}$ (PKC) and protein kinase A (PKA) pathways are highly associated with disordered ZPIAR in normozoospermic infertile men with normal sperm-ZP binding. They also found that phorbol myristate acetate (PMA, PKC activator) and dibutyryl cyclic AMP (AMP, PKA activator) enhanced acrosome reaction among DZIPAR infertile men. ${ }^{[30]}$ Gupta et al.$^{[31]}$ underlined the understanding the role of ZP glycoproteins during human fertilization in facilitating the development of new contraceptives and strategies to overcome the problem of infertility.

\section{Role of Zonadhesin during sperm-ovum binding}

Zonadhesin is an intra-acrosomal protein. The binding capacity of zonadhesin to ZP was firstly shown in pigs, then in many other animals and most recently in humans. ${ }^{[32]}$ Zonadhesin is the only sperm protein that shows species specificity in terms of binding to $\mathrm{ZP}$ and it is produced during spermatogenesis in the early spermatid period. ${ }^{[33]}$ It is located at the apical head of spermatozoa and released into the seminiferous tubule. Spermegg interaction is assessed by analyzing this protein during fertilization.

Tardif et al ${ }^{[34]}$ proposed a model in which sperm could be transiently exposed to acrosomal molecules that adhere to the zona independent from the AR in a 'kiss and run' mechanism. They concluded that this could be important for further investigations and a detailed understanding of the molecular events during sperm-ovum binding is likely to provide new approaches for the design of more effective male contraceptives and better diagnostic methods for sperm dysfunction. ${ }^{[34]}$

\section{Acrosome reaction}

Sperm binding to the ZP triggers the hydrolyzing enzymes known as AR (Figure 4) and only acrosome-reacted spermatozoa can penetrate $\mathrm{ZP}$, bind the oocyte membrane and fuse with oocyte. ${ }^{[35]}$ The release of lytic enzymes and the presence of membrane receptors are required for the acrosome reaction, resulting in penetration of sperm through $\mathrm{ZP}$ and integration with the oolema. ${ }^{[36]}$ The AR begins at the $\mathrm{ZP}$ after sperm bind- 
ing. Acrosomal status can be assessed by microscopy, flow cytometry and fluorescently labeled lectins. Calculating the percentage of damaged acrosome containing cells in fresh and stored semen is one of the most important parts of semen assessment.

Similar to zona binding tests, patients with poor AR test should be referred to ICSI. Meta-analysis revealed a high predictive power for AR tests for the prediction of fertilization. ${ }^{[8]}$ In a total of 797 subjects, ROC curve showed higher PPV ( $>75 \%)$, NPV $(>65 \%), 80 \%$ sensitivity and $20 \%$ false-positive rates. Nevertheless, AR is currently used for research purposes rather than clinical purposes.

\section{Hyaluronan binding assay (HBA)}

This test is based on the binding of hyaluronic acid to sperm with better morphological features and intact acrosome. ${ }^{[37]}$ Hyaluronic acid (HA) surrounds the human oocyte and acts as a natural spermatozoa selector. Human spermatozoa express HA receptors and only spermatozoa with normal shape, minimal DNA fragmentation and lesser chromosomal aneuploidies can bind to HA. Spermatozoa, expressing the HA receptor and having hyaluronidase activity at high levels, are more likely to pass the extracellular matrix, bind to the ZP and fertilize the ovum. ${ }^{[38]}$

In hyaluronan binding assay (HBA), HA is binded by human spermatozoa and indicates the presence of cellular maturity, viability and spermatozoa with intact acrosomes because HA is the main component of extracellular matrix of cumulus oophorus. Intact HA binding sites on the sperm plasma membrane indicate sperm maturity. ${ }^{[37]}$ Therefore, HBA is a reliable and reproducible test to identify IVF or ICSI candidates. ${ }^{[37]}$

Two methods have been examined for the selection of ideal sperm with high expression of HA activity: a HA culture dish

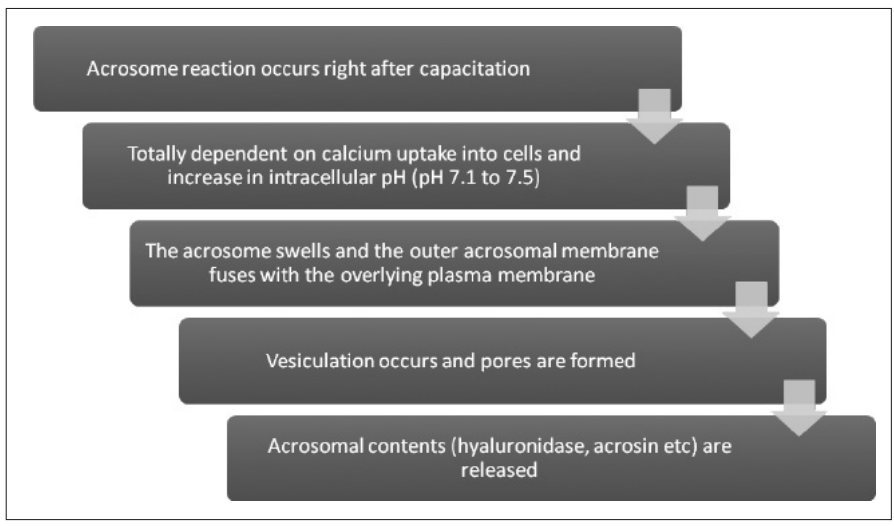

Figure 4. Steps of acrosome reaction
(PICSI [physiological intracytoplasmic sperm injection] Sperm Selection Device) and viscous medium containing HA (Sperm Slow). HA sperm are bound by the head to the bottom, however, in Sperm-Slow HA, spermatozoa has a very slow motility. However, in clinical practice the authors concluded that the rates of achieving embryos of improved quality were similiar between two groups. ${ }^{[39]}$

Hyaluronic acid is also found in cervical mucus and oviductal fluid. It has been demonstrated that human spermatozoa expressing HA receptor (CD44) display better plasma membrane structure, mitochondrial membrane potential, fertilization potential and maturation characteristics compared to non-CD44. ${ }^{[40]}$ Therefore, CD44 present in the spermatozoa is a good indicator of sperm quality, which is also recognized by the female genital tract.

Evidence is insufficient to show whether sperm selection by HA binding improves live birth or pregnancy rates in ART. There is also no sufficient evidence to show difference in efficiacy between the HA binding methods SpermSlow and PICSI. No randomised evidence describes the evaluation of sperm selection by sperm apoptosis, sperm birefringence or surface charge. [41]

\section{Hypo-osmotic Swelling Test}

Hypo-osmotic swelling test (HOST) is based on the intact membranes of the viable spermatozoa. An intact sperm membrane plays an important role during fertilization. HOST is indicated in cases with very few or no motile sperm in the ejaculate. In hypo-osmotic conditions, intact sperm cell's cytoplasmic space swells and its tail curls. Dead sperm with non-intact membrane can not swell in hypotonic media and exhibits these features (Figure 5).The results of this test correlate with other semen assessments such as morphology and motility, but the data on its effecs on fertility are not satisfactory. ${ }^{[42]}$

\section{Magnetic-activated cell sorting}

Magnetic-activated cell sorting (MACS) depends on selecting preferred cells based on membrane surface markers. In this assay, healthy spermatozoa are separated magnetically by maintaining the structure, viability and functioning of the spermatozoa (Figure 6).

In somatic cells, normally, phosphatidylserine (PS) is located in the internal layer of plasma membrane. Externalization of PS from inner to outer layer of plasma membrane can be assessed by Annexin $\mathrm{V}$ and is considered as one of the early signs of apoptosis before capacitation. ${ }^{[43]}$ However, this process is a nor- 




Figure 5. The flow chart of hypo-osmotic swelling test

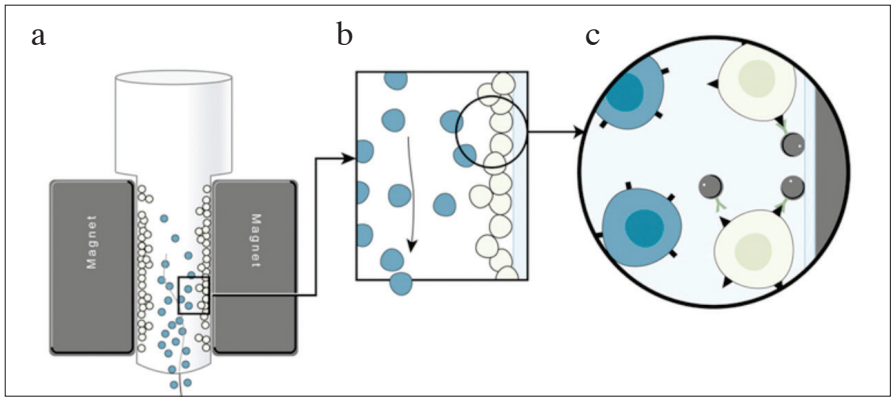

Figure 6. Magnetic-Activated Cell Sorting. (a) Annexin V molecule is attached to magnetic microspheres (b) When sperm go through a magnetic field, those who attach to the microspheres are retained and discarded (c) Annexin V binds to a marker (phosphatidylserine) present only in the membrane of sperm with fragmented DNA

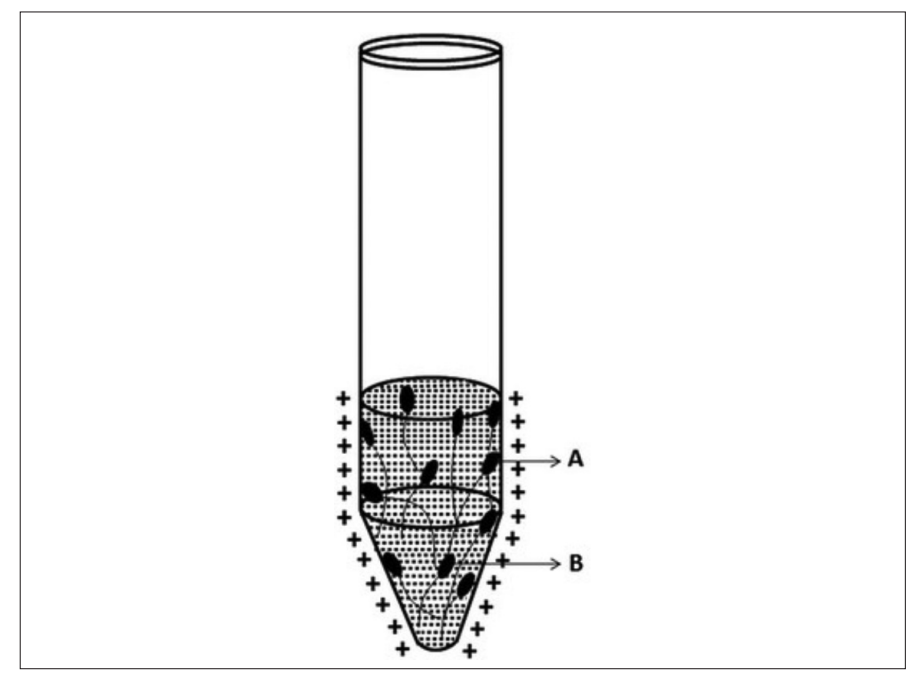

Figure 7. Sperm selection using zeta test. (A) Negatively charged mature sperm will move to the positively charged tube surface. (B) Immature spermatozoa will be discarded mal phenomenon observed during capacitation. This dual functioning role of PS in human spermatozoa makes interpretation and test design very difficult. At this point, MACS can isolate sperm at the molecular level using Annexin $\mathrm{V}^{[44]}$

Said et al. ${ }^{[45]}$ reported higher embryo cleavage and pregnancy, but lower fertilization or implentation rates with MACS technique. It has been emphasized that the MACS assay has the potential to isolate spermatozoa with normal acrosomes and protamine content and to have a higher significance in severe teratozoospermic patients..$^{[46]}$

\section{Zeta sperm selection}

A mature sperm possess a surface electric charge ranging from -16 to $-20 \mathrm{mV}$, termed as the zeta potential which decreases with capacitation. ${ }^{[4]}$ Normally differentiated sperms are charged electronegatively (Figure 7). Many studies have shown that sperms selected according to the membrane zeta potential levels exhibit lower DNA fragmentation. ${ }^{[48]}$ From this point of view, sperm selection according to electric charge could improve the ICSI results.

Sperm with high negative surface electrical charge are mature and more likely to have intact chromatin. In a recent prospective study, a total of 203 ICSI cycles studied, 101 cycles were included to density gradient centrifugation (DGC)/Zeta group and the remaining 102 in the DGC group. The authors observed a significant increase in top quality embryos and pregnancy rates in the DGC/Zeta group compared to DGC group. They concluded that zeta method improves the percentage of embryo quality and pregnancy outcomes. ${ }^{[49]}$ Some substantial studies evaluating sperm function tests are summarized in Table 1.

In conclusion, sperm function tests have a role in further evaluation of infertile couples. It is not always possible to predict pregnancy outcomes by conventional semen analysis due to multifactorial nature of fertilization. Therefore, functional tests evaluating the male fertility potential at the molecular and cellular level are of importance. On the other hand, these tests have some limitations: standardization is required in methodologies, some tests are useless, expensive and time consuming and human material is required. The development of molecular biology techniques and the optimization of these tests will lead to novel diagnostic and therapeutic improvements in the management of male factor infertility.

With the advances in technology, to take part in routine clinical practice, these tests must be (i) accurate; (ii) cost-effective; (iii) easy to use; and (iv) clinically useful. 
Table 1. Studies evaluating sperm function tests

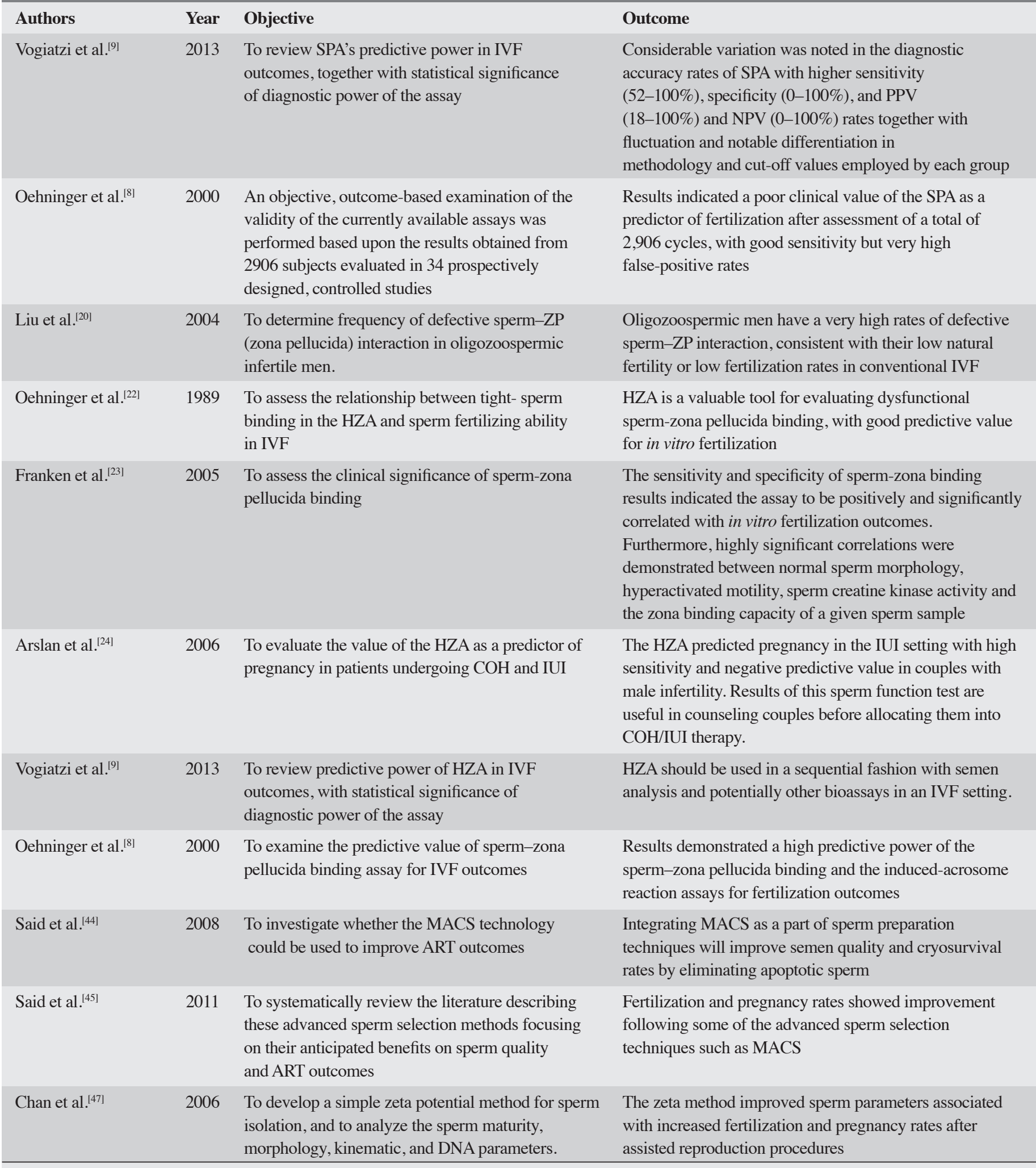

SPA: sperm penetration assay; IVF: in vitro fertilization; HZA: hemizona assay; $\mathrm{COH}$ : controlled ovarian hyperstimulation; IUI: intrauterine insemination; MACS: magnetic activated cell sorter; ART: assisted reproductive technique; PPV: positive predictive value; NPV: negative predictive value 
Peer-review: This manuscript was prepared by the invitation of the Editorial Board and its scientific evaluation was carried out by the Editorial Board.

Author Contributions: Concept - F.K., B.A.; Design - B.A.; Supervision - B.A.; Resources - B.A.; Materials - F.K., B.A.; Data Collection and/or Processing-F.K., B.A.; Analysis and/or Interpretation - F.K., B.A.; Literature Search - F.K.; Writing Manuscript - F.K., B.A.; Critical Review - B.A.

Conflict of Interest: No conflict of interest was declared by the authors.

Financial Disclosure: The authors declared that this study has received no financial support.

\section{References}

1. Lefièvre L, Bedu-Addo K, Conner SJ, Machado-Oliveira GS, Chen Y, Kirkman-Brown JC, et al. Counting sperm does not add up any more: time for a new equation? Reproduction 2007;133:675-84.

2. Guzick DS, Overstreet JW, Factor-Litvak P, Brazil CK, Nakajima ST, Coutifaris C, et al. Sperm morphology, motility, and concentration in fertile and infertile men. N Engl J Med 2001;345:138893. [Crossref]

3. Oehninger S. Clinical management of male infertility in assisted reproduction: ICSI and beyond. Int J Androl 2011;34:e319-e29.

4. Barratt CL, Mansell S, Beaton C, Tardif S, Oxenham SK. Diagnostic tools in male infertility--the question of sperm dysfunction. Asian J Androl 2011;13:53-8. [Crossref]

5. González-Marín C, Gosálvez J, Roy R. Types, causes, detection and repair of DNA fragmentation in animal and human sperm cells. Int J Mol Sci 2012;13:14026-52. [Crossref]

6. Shu JH, Feng GX, Li J, Li JX, Gan XY, Zhang B, et al. Predictive value of sperm morphology according to WHO Laboratory Manual for the Examination and Processing of Human Semen (5th Ed) on the outcomes of IVF-ET. Zhonghua Nan Ke Xue 2013;19:414-7.

7. Rogers BJ, van Campen H, Ueno M, Lambert H, Bronson R, Hale $\mathrm{R}$. Analysis of human spermatozoal fertilizing ability using zonafree ova. Fertil Steril 1979;32:664-70. [Crossref]

8. Oehninger S, Franken DR, Sayed E, Barroso G, Kolm P. Sperm function assays and their predictive value for fertilization outcome in IVF therapy: a meta-analysis. Hum Reprod Update 2000;6:160-8. [Crossref]

9. Vogiatzi P, Chrelias C, Cahill DJ, Creatsa M, Vrachnis N, Iliodromiti $\mathrm{Z}$, et al. Hemizona assay and sperm penetration assay in the prediction of IVF outcome: a systematic review. BioMed Res Int 2013;2013:945825. [Crossref]

10. Oehninger S, Franken DR, Ombelet W. Sperm functional tests. Fertil Steril 2014;102:1528-33. [Crossref]

11. Mol B, Meijer S, Yuppa S, Tan E, De Vries J, Bossuyt P, et al. Sperm penetration assay in predicting successful in vitro fertilization. A meta-analysis. J Reprod Med 1998;43:503-8.

12. Aron J, Smith RG, Bassham B, Lipshultz LI, Lamb DJ. The microsperm penetration assay: development of a sperm pen- etration assay suitable for oligospermic males. Fertil Steril 1991;56:528-34. [Crossref]

13. Oehninger S. Clinical and laboratory management of male infertility: an opinion on its current status. J Androl 2000;21:814-21.

14. Oehninger S. Molecular basis of human sperm-zona pellucida interaction. Cells Tissues Organs 2001;168:58-64. [Crossref]

15. Burkman LJ, Coddington CC, Franken DR, Kruger TF, Rosenwaks $\mathrm{Z}$, Hodgen GD. The hemizona assay (HZA): development of a diagnostic test for the binding of human spermatozoa to the human hemizona pellucida to predict fertilization potential. Fertil Steril 1988;49:688-97. [Crossref]

16. Liu DY, Lopata A, Johnston WIH, Baker HG. A human spermzona pellucida binding test using oocytes that failed to fertilize in vitro. Fertil Steril 1988;50:782-8. [Crossref]

17. Liu DY, Garrett C, Baker HG. Clinical application of spermoocyte interaction tests in in vitro fertilization-embryo transfer and intracytoplasmic sperm injection programs. Fertil Steril 2004;82:1251-63. [Crossref]

18. Liu DY, Baker HG. Andrology: Disordered acrosome reaction of spermatozoa bound to the zona pellucida: a newly discovered sperm defect causing infertility with reduced sperm-zona pellucida penetration and reduced fertilization in vitro. Hum Reprod 1994;9:1694-700. [Crossref]

19. Franken D, Oosthuizen W, Cooper S, Kruger T, Burkman L, Coddington $\mathrm{C}$, et al. Electron microscopic evidence on the acrosomal status of bound sperm and their penetration into human hemizonae pellucida after storage in a buffered salt solution. Andrologia 1991;23:205-8. [Crossref]

20. Liu DY, Baker HG. High frequency of defective sperm-zona pellucida interaction in oligozoospermic infertile men. Hum Reprod 2004;19:228-33. [Crossref]

21. Oehninger S, Morshedi M, Franken D. The hemizona assay for assessment of sperm function. Spermatogenesis: Methods and Protocols 2013.91-102.

22. Oehninger S, Coddington CC, Franken DA, Scott R, Burkman LJ, Acosta AA, et al. Hemizona assay: assessment of sperm dysfunction and prediction of in vitro fertilization outcome. Fertil Steril 1989;51:665-70. [Crossref]

23. Franken D, Oehninger S. The clinical significance of sperm-zona pellucida binding: 17 years later. Front Biosci 2006;11:1227-33. [Crossref]

24. Arslan M, Morshedi M, Arslan EO, Taylor S, Kanik A, Duran HE, et al. Predictive value of the hemizona assay for pregnancy outcome in patients undergoing controlled ovarian hyperstimulation with intrauterine insemination. Fertil Steril 2006;85:1697-707. [Crossref]

25. Oehninger S, Morshedi M, Franken D. The hemizona assay for assessment of sperm function. Methods Mol Biol 2013;927:91-102. [Crossref]

26. Liu D, Garrett C, Baker H. Acrosome-reacted human sperm in insemination medium do not bind to the zona pellucida of human oocytes. Int J Androl 2006;29:475-81. [Crossref]

27. Lefievre L, Conner S, Salpekar A, Olufowobi O, Ashton P, Pavlovic B, et al. Identification of four glycoproteins in the human zona pellucida by proteomic analysis of five oocytes. Hum Reprod 2004;19:1580-6. [Crossref] 
28. Yauger B, Boggs NA, Dean J. Human ZP4 is not sufficient for taxon-specific sperm recognition of the zona pellucida in transgenic mice. Reproduction 2011;141:313-9. [Crossref]

29. Liu DY, Liu ML, Garrett C, Baker HG. Comparison of the frequency of defective sperm-zona pellucida (ZP) binding and the ZP-induced acrosome reaction between subfertile men with normal and abnormal semen. Hum Reprod 2007;22:1878-84. [Crossref]

30. Liu DY, Liu ML, Baker HG. Defective protein kinase A and C pathways are common causes of disordered zona pellucida (ZP)induced acrosome reaction in normozoospermic infertile men with normal sperm-ZP binding. Fertil Steril 2013;99:86-91. [Crossref]

31. Gupta SK. Role of zona pellucida glycoproteins during fertilization in humans. J Reprod Immunol 2015;108:90-7. [Crossref]

32. Tardif S, Brady HA, Breazeale KR, Bi M, Thompson LD, Bruemmer JE, et al. Zonadhesin D3-polypeptides vary among species but are similar in Equus species capable of interbreeding. Biol Reprod 2010;82:413-21. [Crossref]

33. Olson GE, Winfrey VP, Bi M, Hardy DM, NagDas SK. Zonadhesin assembly into the hamster sperm acrosomal matrix occurs by distinct targeting strategies during spermiogenesis and maturation in the epididymis. Biol Reprod 2004;71:1128-34. [Crossref]

34. Tardif S, Cormier N. Role of zonadhesin during sperm-egg interaction: a species-specific acrosomal molecule with multiple functions. Mol Hum Reprod 2011;17:661-8. [Crossref]

35. Yanagimachi R. Mammalian fertilization. The physiology of reproduction 1994:189-317.

36. Esteves SC, Sharma RK, Thomas Jr AJ, Agarwal A. Effect of in vitro incubation on spontaneous acrosome reaction in fresh and cryopreserved human spermatozoa. Int J Fertil Womens Med 1997;43:235-42.

37. Huszar G, Ozenci CC, Cayli S, Zavaczki Z, Hansch E, Vigue L. Hyaluronic acid binding by human sperm indicates cellular maturity, viability, and unreacted acrosomal status. Fertil Steril 2003;79:1616-24. [Crossref]

38. Myles DG, Primakoff P. Why did the sperm cross the cumulus? To get to the oocyte. Functions of the sperm surface proteins PH-20 and fertilin in arriving at, and fusing with, the egg. Biol Reprod 1997;56:320-7. [Crossref]

39. Parmegiani L, Cognigni GE, Bernardi S, Troilo E, Taraborrelli
$\mathrm{S}$, Arnone A, et al. Comparison of two ready-to-use systems designed for sperm-hyaluronic acid binding selection before intracytoplasmic sperm injection: PICSI vs. Sperm Slow: a prospective, randomized trial. Fertil Steril 2012;98:632-7. [Crossref]

40. Liu Y, Long Y, Liu M, Chen XL, Wu WY, Cheng JE. Quality characteristics of human spermatozoa with hyaluronic acid receptors. Zhonghua Nan Ke Xue 2014;20:37-43.

41. McDowell S, Kroon B, Ford E, Hook Y, Glujovsky D, Yazdani A. Advanced sperm selection techniques for assisted reproduction. Cochrane Database Syst Rev 2013;10.

42. Goericke-Pesch S, Failing K. Retrospective analysis of canine semen evaluations with special emphasis on the use of the hypoosmotic swelling (HOS) test and acrosomal evaluation using Spermac®. Reprod Domest Anim 2013;48:213-7. [Crossref]

43. Zahedi A, Tavalaee M, Deemeh M, Azadi L, Fazilati M, NasrEsfahani M. Zeta potential vs apoptotic marker: which is more suitable for ICSI sperm selection? J Assist Reprod Genet 2013;30:1181-6.

44. Said TM, Agarwal A, Zborowski M, Grunewald S, Glander HJ, Paasch U. Utility of magnetic cell separation as a molecular sperm preparation technique. J Androl 2008;29:134-42. [Crossref]

45. Said TM, Land JA. Effects of advanced selection methods on sperm quality and ART outcome: a systematic review. Hum Reprod Update 2011;17:719-33. [Crossref]

46. Zahedi A, Tavalaee M, Deemeh MR, Azadi L, Fazilati M, NasrEsfahani MH. Zeta potential vs apoptotic marker: which is more suitable for ICSI sperm selection? J Assist Reprod Genet 2013;30:1181-6.

47. Chan PJ, Jacobson JD, Corselli JU, Patton WC. A simple zeta method for sperm selection based on membrane charge. Fertil Steril 2006;85:481-6. [Crossref]

48. Razavi SH, Nasr-Esfahani MH, Deemeh MR, Shayesteh M, Tavalaee M. Evaluation of zeta and HA-binding methods for selection of spermatozoa with normal morphology, protamine content and DNA integrity. Andrologia 2010;42:13-9.[Crossref]

49. Nasr Esfahani MH, Deemeh MR, Tavalaee M, Sekhavati MH, Gourabi H. Zeta Sperm Selection Improves Pregnancy Rate and Alters Sex Ratio in Male Factor Infertility Patients: A DoubleBlind, Randomized Clinical Trial. Int J Fertil Steril 2016;10:25360. 